\title{
Energy and Economic Growth, Is There a Connection? Energy Supply Threats Revisited*
}

\author{
Paul Ojeaga1\#, Deborah Odejimi' ${ }^{2}$, Emmanuel George ${ }^{3}$, Dominic Azuh ${ }^{3}$ \\ ${ }^{1}$ Bergamo University, Bergamo, Italy \\ ${ }^{2}$ Igbinedion University, Okada, Nigeria \\ ${ }^{3}$ Covenant University, Ota, Nigeria \\ Email: "paul.ojeaga@unibg.it, ixerxes2001@yahoo.com
}

Received 26 July 2014; revised 29 August 2014; accepted 3 September 2014

Copyright @ 2014 by authors and Scientific Research Publishing Inc.

This work is licensed under the Creative Commons Attribution International License (CC BY).

http://creativecommons.org/licenses/by/4.0/

(c) ()

\begin{abstract}
The increased cost of accessing energy and the effects on economic growth (GDP) across regions is one of grave concern [1]. The Cost implication of energy supply often shapes regional energy policies across the globe. This paper presents an empirical investigation into the relationship between energy generation and economic growth, while also investigating probable threats to sustainable energy supply across regions. Energy generation was found to have some implications for economic growth across regions. It was found that hydro electric, renewable energy and nuclear generation sources were significantly driving growth across regions while coal and gas sources were not. This was particularly true since the cost of fossils was having strong cost implications, for overall energy generation cost in countries in regions due to overdependence on fossils. Generating sources were also found to have strong implications for sustained energy supply (energy security), renewable energy and gas generating sources that had the strongest effects on sustainable energy supply across regions. This was probably true since regions were focusing on new technologies in energy generation process, which are cheaper, cleaner and more sustaining, while still depending on gas plants due to the relative cost implications of maintaining gas plants compared to hydro and nuclear generating plants. The method of estimation used in the study is the seemingly unrelated regression estimation method.
\end{abstract}

\section{Keywords}

Energy Security, Energy Cost Reduction, Fossils, Growth, Renewable Energy

\footnotetext{
*This section introduces the trends in energy consumption, supply and generation across regions.

"Corresponding author.
} 


\section{Introduction}

Lots of studies have already argued that energy generation has strong cost implication for private-sector driven growth. There also is an ongoing debate as to what exactly are the threats to sustainable energy supply [2], since the cost of generation can have strong implications for energy stakeholders and policy makers. While many studies have studied the impact of energy generation on growth, few studies have attempted to study the impact of different energy sources on growth, particularly as it affects regional growth as a main point of focus.

Issues of sustainability are also ones of paramount importance, and overdependence on fossils also means that susceptibility to failure in energy generation and supply risks is also increasing since issues of cost and political disputes e.g. the Russo-Ukrainian gas dispute of 2005/2006, can affect gas supplies across regions. While the use of fossils continues to have strong consequences for energy security, it is likely to have little or no effect on growth due to the cost implication of acquiring fossils for the energy generation process.

Environmental constraints, industrialization rate, domestic consumption characteristics and regional specific investment in domestic technology are possible determinants of energy availability across regions [1]. Global demands for energy are also on the increase in United Nations energy report 2012, making World energy consumption to have doubled by the year 2050.

Numerous literatures also continue to argue for diversification away from fossils due to overdependence [3], stating that diversification can lead to sustained supply and mitigate future risk of energy shortage attributable to cost related factors that affect gas supply availability. Other causal empirical studies, [4] also show that diversification is also on the increase in developed countries particularly the United States.

While fears of increased demands in the domestic energy markets of major exporters continue to increase, studies show that such demands are not likely to affect energy security on the short-run [5]-[7], since consuming countries are likely to shift to new exporters. In an attempt to study the cost reduction of the energy generation, [8] also argued extensively that inter-fuel substitution between oil and gas was of little significance compared to inter-fuel substitution between electricity and oil making fossils to have strong consequence for the electricity generation process.

The paper by [9] also studied the impact of portfolio diversity on cost for energy-importing countries and stated that consumer countries should hold portfolios free of cost risk associated with the hike in fossil fuel prices. The study by [10] also attempted to study the effects of cross-country energy policy on energy security from country-specific perspective, to energy vulnerability aversion, and they found that energy security had actually been affected by country-specific domestic consumption and reliance on specific sources for energy generation.

Many factors are known to affect growth across regions, while the neoclassical growth theory is based on the premise that technology is fixed across countries, and places strong emphasis on the importance of capital on growth, and the endogenous growth theory argues extensively on the importance that skill development can have on growth.

This paper examines the link between growth and energy generation across regions, and lots of factors have already been identified to affect growth across regions. They include: domestic energy consumption rate, industrialization rate, investment in domestic technology to boost energy generation, access to energy generation sources and other climatic concerns. The method of estimation used is the seemingly unrelated regression estimation method which has obvious advantages since it reduces the bias in two unrelated dependent variables of a simultaneous equation regression through the interaction of their errors with one another producing consistent estimates. The rest of the paper is divided into its scope and overview of study, empirical analysis and finally the concluding sections.

\section{Overview of Study}

\subsection{Scope and Objective of Study}

The scope of the paper presents empirical evidence on the energy generation and growth and revisits threats to sustained energy supply across regions previous addressed by [11]. The objectives of the study include:

1) Does energy generation affect growth across regions?

2) What energy generation sources are relevant to driving growth across regions?

3) Do threats identified as risk to energy supply matter in increasing supply risks across regions? 


\subsection{Stylized Facts on Energy Security and Growth across Regions}

In this section we present the stylized facts on energy security and growth across regions. World energy generation capability is on the increase, with output energy in Asia likely to surpass total generation in Europe and North America by 2040 (see Table 1) that growth across regions is on the increase except for Africa (see Figure 1 id 3), while growth is on the increase in North America, European, Union, Latin America and South East Asia. Most countries in Africa remain poor despite sustained commodities high prices in the global market. In many countries that are experiencing growth in Africa the growth is also not inclusive.

Table 1. World installed generating capacity by region and country, 2010-2040.

\begin{tabular}{|c|c|c|c|c|c|c|c|c|}
\hline \multirow{2}{*}{ OECD } & \multicolumn{7}{|c|}{ Projections } & \multirow{2}{*}{$\begin{array}{l}\text { Yearly \% } \\
\text { Changes }\end{array}$} \\
\hline & 2010 & 2015 & 2020 & 2025 & 2030 & 2035 & 2040 & \\
\hline OECD Americas & 1248 & 1316 & 1324 & 1379 & 1456 & 1546 & 1669 & 1.0 \\
\hline United States $^{\mathrm{a}}$ & 1033 & 1080 & 1068 & 1098 & 1147 & 1206 & 1293 & 0.8 \\
\hline Canada & 137 & 144 & 152 & 163 & 174 & 185 & 198 & 1.2 \\
\hline Mexico/Chile & 78 & 93 & 104 & 118 & 135 & 155 & 177 & 2.8 \\
\hline OECD Europe & 946 & 1028 & 1096 & 1133 & 1159 & 1185 & 1211 & 0.8 \\
\hline OECD Asia & 441 & 444 & 473 & 489 & 501 & 516 & 524 & 0.6 \\
\hline Japan & 287 & 275 & 293 & 300 & 304 & 309 & 306 & 0.2 \\
\hline South Korea & 85 & 93 & 100 & 107 & 114 & 122 & 130 & 1.5 \\
\hline Australia/New Zealand & 69 & 76 & 81 & 83 & 83 & 85 & 87 & 0.8 \\
\hline Total OECD & 2635 & 2788 & 2894 & 3002 & 3116 & 3247 & 3403 & 0.9 \\
\hline \multicolumn{9}{|l|}{ Non-OECD } \\
\hline Non-OECD Europe and Eurasia & 408 & 421 & 455 & 480 & 508 & 538 & 563 & 1.1 \\
\hline Russia & 229 & 239 & 264 & 282 & 299 & 315 & 325 & 1.2 \\
\hline Other & 179 & 182 & 191 & 198 & 209 & 223 & 239 & 1.0 \\
\hline Non-OECD Asia & 1452 & 1820 & 2188 & 2479 & 2772 & 3057 & 3277 & 2.8 \\
\hline China & 988 & 1301 & 1589 & 1804 & 2007 & 2176 & 2265 & 2.8 \\
\hline India & 208 & 241 & 285 & 327 & 376 & 440 & 510 & 3.0 \\
\hline Other & 256 & 278 & 314 & 347 & 390 & 441 & 502 & 2.3 \\
\hline Middle East & 185 & 197 & 216 & 233 & 247 & 267 & 280 & 1.4 \\
\hline Africa & 134 & 147 & 164 & 184 & 211 & 244 & 283 & 2.5 \\
\hline Central and South America & 247 & 279 & 304 & 329 & 362 & 400 & 447 & 2.0 \\
\hline Brazil & 114 & 137 & 152 & 169 & 191 & 221 & 256 & 2.8 \\
\hline Other & 134 & 142 & 152 & 160 & 171 & 179 & 191 & 1.2 \\
\hline Total Non-OECD & 2426 & 2864 & 3327 & 3705 & 4099 & 4505 & 4850 & 2.3 \\
\hline Total World & 5061 & 5652 & 6221 & 6707 & 7214 & 7752 & 8254 & 1.6 \\
\hline
\end{tabular}

${ }^{\mathrm{a}}$ Includes the 50 states and the District of Columbia. Note: Totals may not equal sum of components due to independent rounding. Sources: History: Derived from U.S. Energy Information Administration (EIA), International Energy Statistics database (as of November 2012), www.eia.gov/ies. Projections: EIA, Annual Energy Outlook 2013, DOE/EIA-0383(2013) (Washington, DC: April 2013); AEO2013 National Energy Modeling System, run REF2013.D102312A, www.eia.gov/aeo; and World Energy Projection System Plus (2013). 


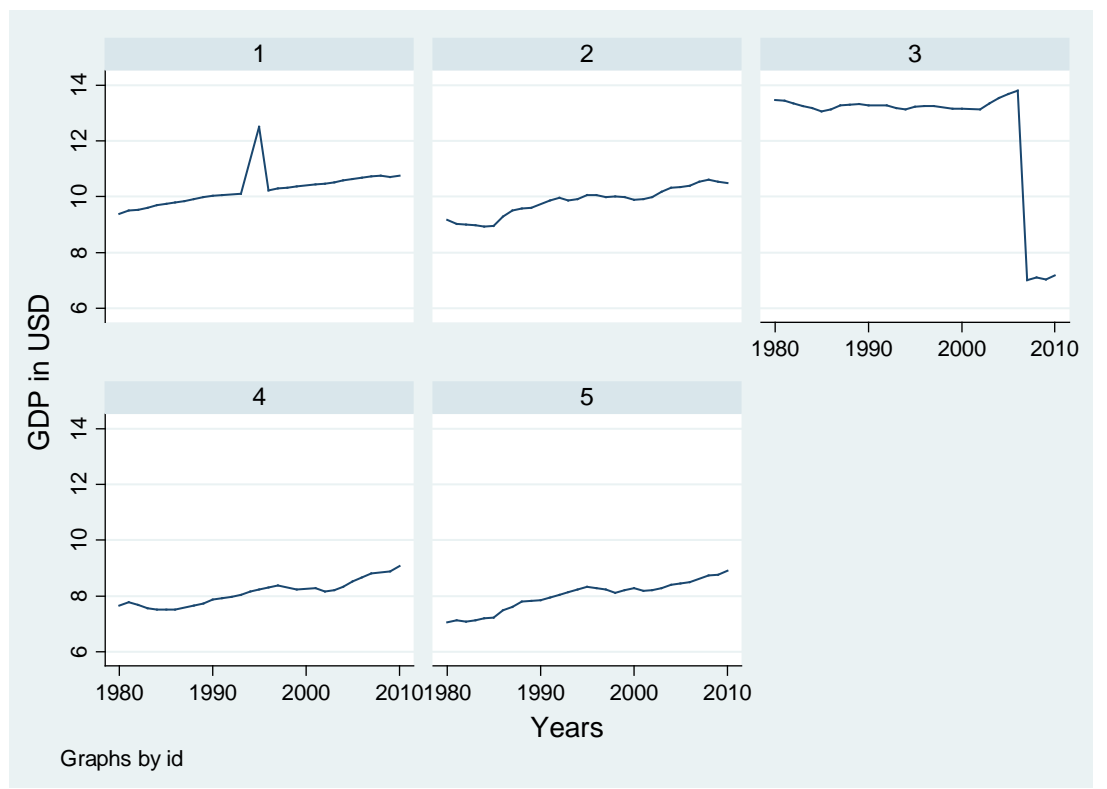

Note: The graphs above show trends for North America, Europe, Africa, Latin America and South East Asia respectively.

Figure 1. Regional GDP trends.

Despite been endowed with enormous natural resources Africa also remains plagued with poor governance and weak institutions making many policies not to have any effect on growth and economic development in the region, [12]-[14]. North America still remains the most productive of all regions this is attributable to high productive of it level force which remains the most productive due to high skill and technological endowments associated with the region [14]. Other regions which include Europe, Latin America and South East Asia are also experiencing significant growth.

Trends also show that energy security is also low for Africa (see Figure 2), depicting poor implementation of the Kyoto Protocol as well as an under developed energy sector plagued with high energy supply and distribution disruptions. Issues associated with the cost implications of developing energy plants is also a problem in many African countries with poor income. The Doha round of talks breakdown will also have strong implications for energy security since major energy consumers e.g. United States and Canada pulled out are not likely to commit to emission reduction targets set by regulatory agencies. Therefore it is not expected that regions are likely to be alive to the negative effects associated with poor energy consumption methods currently on grounds which can lead to potential supply problems in the future.

The rapid industrialization in Latin America, South East Asia and also in some emerging African countries starting in the early 2000s, see id 3, 4 and 5 respectively in Figure 8, also means that the competition for the world resources is on the increase despite the slowdown in the industrialization development of the highly developed countries in Europe and North America (see id 1 and 2 in Figure 3). Investment in domestic technology in regions is also ongoing with a steady rate of investment in Europe and North America and continuous improvement for Latin America and Africa. North America particularly the United States and Canada have some of the largest number of Wind generating plants in the World after China [15]. Asia is presently experiencing a slowdown from the massive investment of the 1990s in generation technology, but still maintaining steady investment in the development of improved generation sources.

North America has the most diversified energy sector with the United States having the highest number of wind farms and hydro power stations in the world (see Figure 2 where energy security is the measure of how diversified the regional generation process is). Europe is also gradually disengaging from the use of nuclear plants in energy generation and introducing renewable energy technology in the energy generation process although it is still vulnerable to strong dependence on Gas production sources [1].

Hydro production capabilities utilization is still reasonably high for North America, Europe, Africa and Latin America (see Figure 3). South East Asia is actually experiencing reduced dependence on hydro generation due 


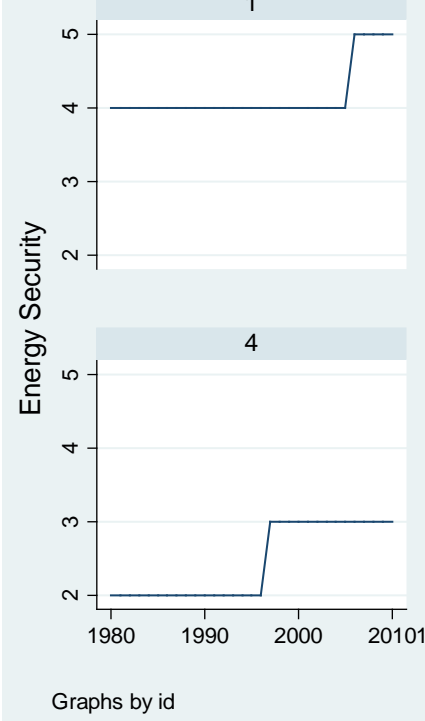

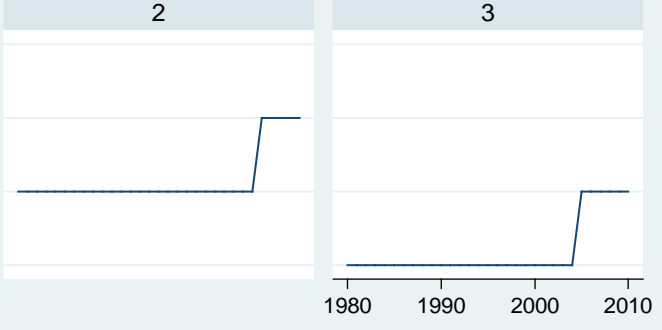

5

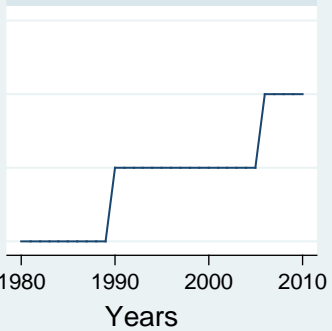

Note: The graphs above show trends for North America, Europe, Africa, Latin America and South East Asia respectively.

Figure 2. Energy security trends across regions.

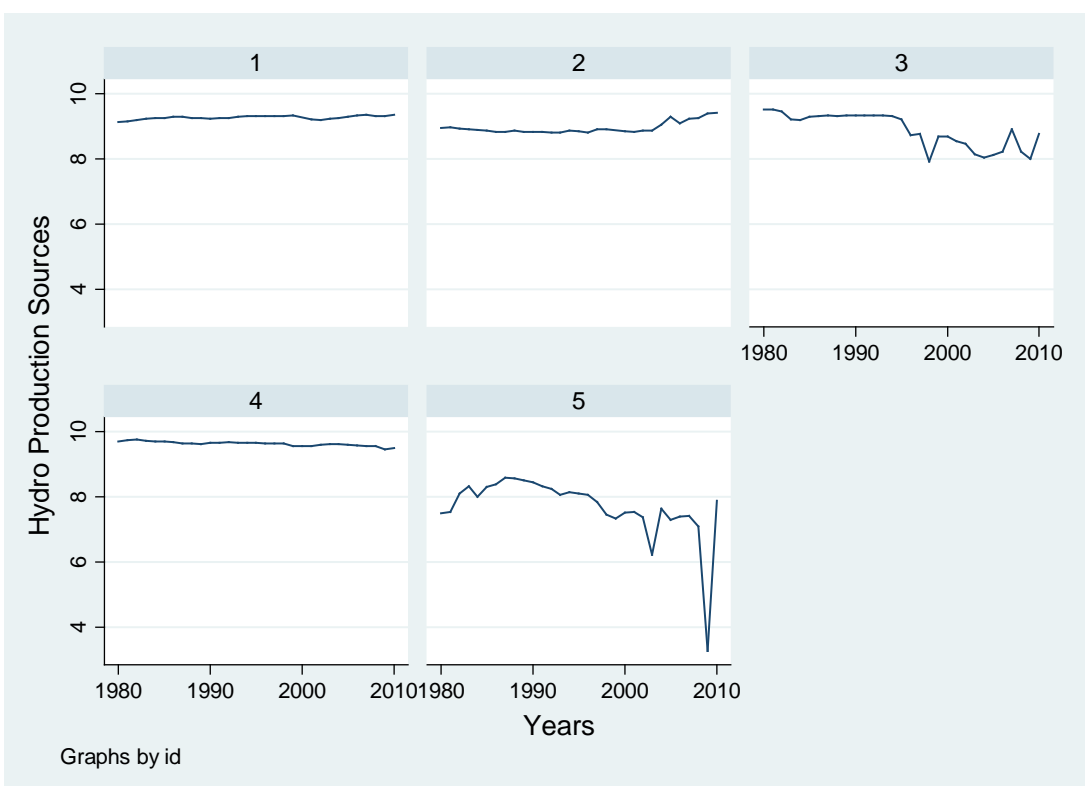

Note: The graphs above show trends for North America, Europe, Africa, Latin America and South East Asia respectively.

Figure 3. Regional hydro generation.

to probably poor natural sources for developing hydro generation plant capabilities. The use of coal in energy generation is also on the increase for all regions except North America and Europe where declines in their use are noticeable (see Figure 4). This is probably due to the advent of alternative means of generation that are cleaner making these highly developed regions to lack further incentives to continue developing more of such plants for future energy use.

Dependence on nuclear generating plants is also on the decrease in all regions except in Africa where only minimal increases were recorded; this is attributable to complexities associated with nuclear waste disposal, cost 
of maintenance and development and finally the high risk associated with operating such plants, making regions not to have sufficient incentive to develop such generating capacities (see Figure 5). Uses of renewable sources were also on the increase except for parts of Asia and Latin America (see Figure 6).

Reliance on gas production sources are also on the increase for all regions except for Africa, this is attributable to the relative ease of development of gas plants and access to gas supplies to power such plants. The use of gas plants in Africa has not experienced commensurate increase compared to other regions due to issues of poor technology and the cost implications of developing such plants since such technologies are often obtained

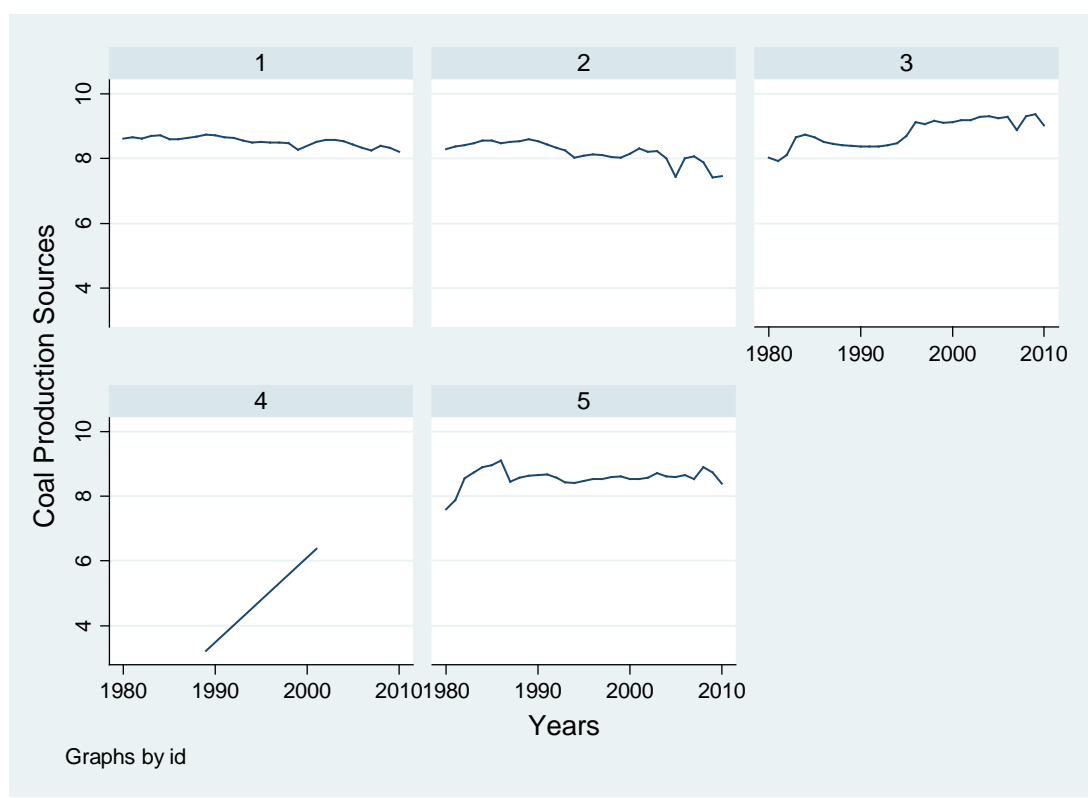

Note: The graphs above show trends for North America, Europe, Africa, Latin America and South East Asia respectively.

Figure 4. Regional coal production.

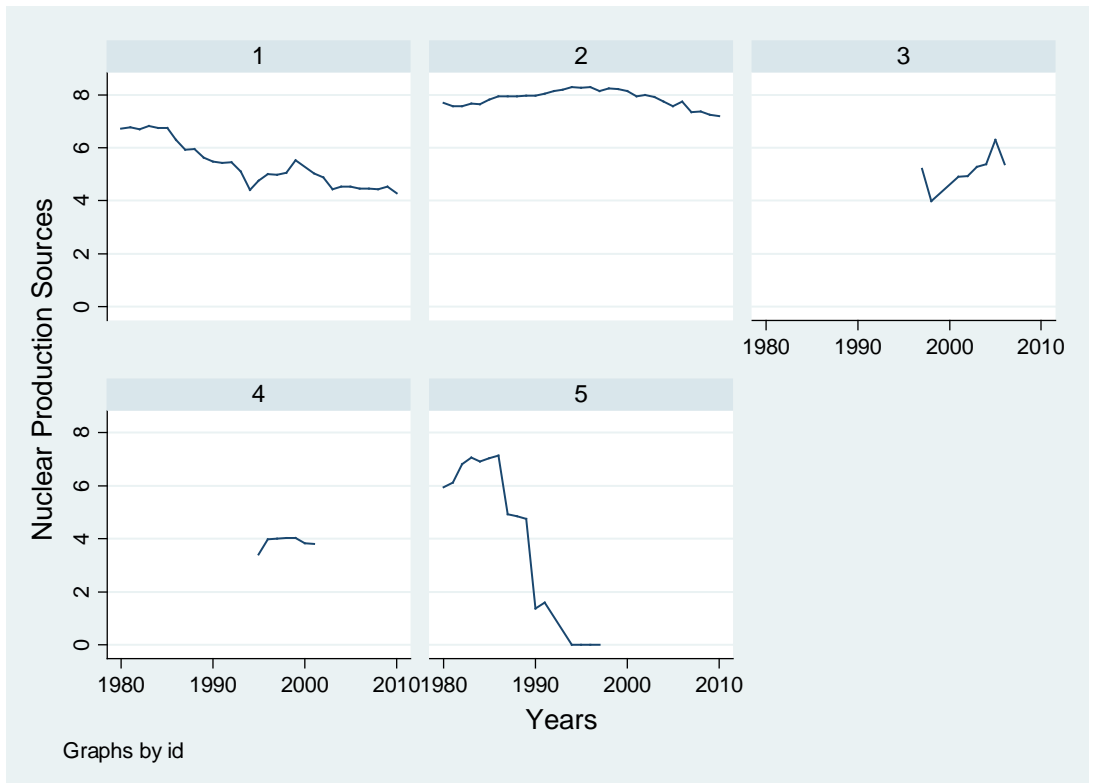

Note: The graphs above show trends for North America, Europe, Africa, Latin America and South East Asia respectively.

Figure 5. Regional nuclear production. 


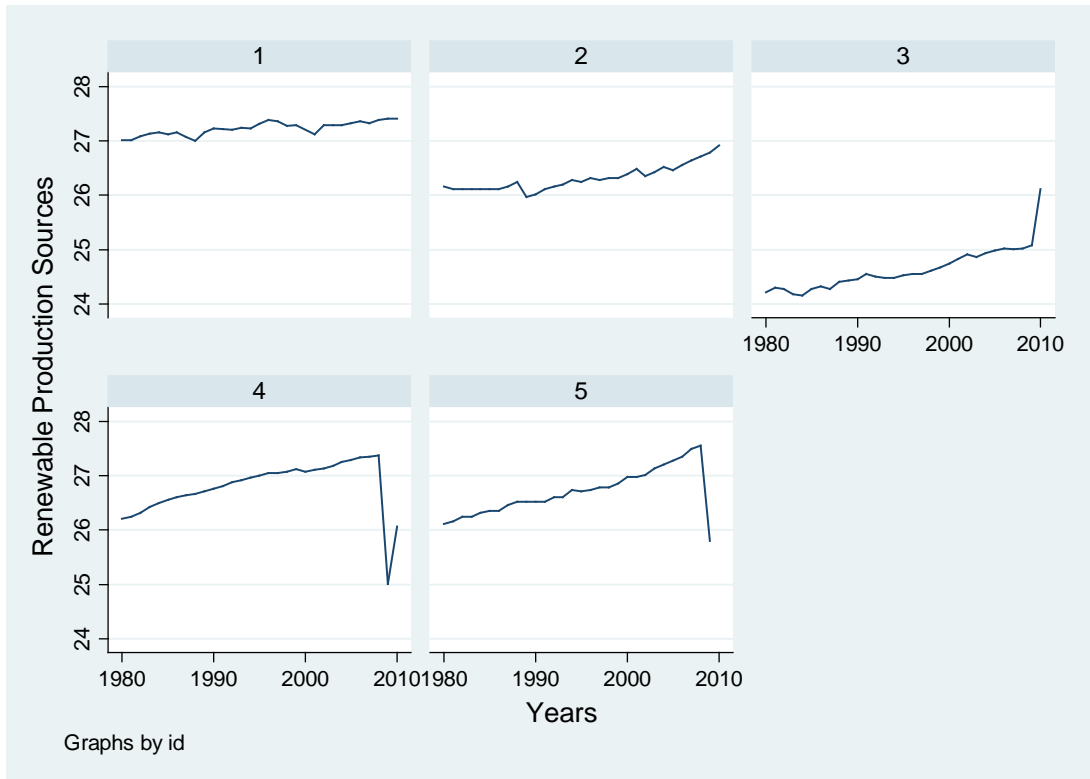

Note: The graphs above show trends for North America, Europe, Africa, Latin America and South East Asia respectively.

Figure 6. Renewable energy production.

overseas (see Figure 7).

Energy use in general across regions is on the increase making regions to be vulnerable. Population growth and industrial development in regions continue to exert strain on current generation infrastructure making countries in regions to be constantly engaged in development of more plants and use of cheaper and alternative methods in the generation process (see Figure 8). Finally an increase in domestic demand is driving generation and development of more energy plants (see Figure 9).

\section{Empirical Analysis and Results}

\subsection{Empirical Analysis}

In this section we present the empirical details used in the study, data for the study is obtained from data market of Iceland for the period of 1980 to 2010, 31 years, for five regions which include for North America, Europe, Africa, Latin America and South East Asia respectively. The dependent variables include energy security (ENSEC) which we measure using score values assigned to regions, based on the level of diversification and infrastructure in renewable energy sources in regions with North America particularly the United States having stronger capabilities towards averting energy interruptions, and economic growth which is the aggregate regional gross domestic product in constant US dollars (USD). We take the logarithm of GDP (Log GDP) due to its noisiness.

Other explanatory variables include cost of accessing energy resources, electricity output generation by source was captured from each generation source such as nuclear plants (Nuclear Prod.), renewable energy sources (particularly wind energy and biogas productions) (Renew Prod. coal powered electric plants (Coal Prod.), gas driven turbines (Gas Prod.) and hydroelectric production (Gas Prod.) which even though classified as renewable was separated from what was called renewable in this study due to strong dependence on hydroelectric generating plants, all measured in kilowatts hours (KWH), environmental constraints (Env. Const.), measured using number of dams, regional size and average regional temperatures that are likely to affect electricity transmissions and consumption particularly for temperate regions were used to generate an index for environmental constraint see [16] for more information on regression residual index generation). Countries, firms and individuals are likely to have fixed budgets, making budget constraints to be an issue for access consumption. For countries the effects will be two fold it will affect the cost of access limiting the amount accessible and it will have negative effect on growth shrinking individual countries in regions budgetary allocation due to the 


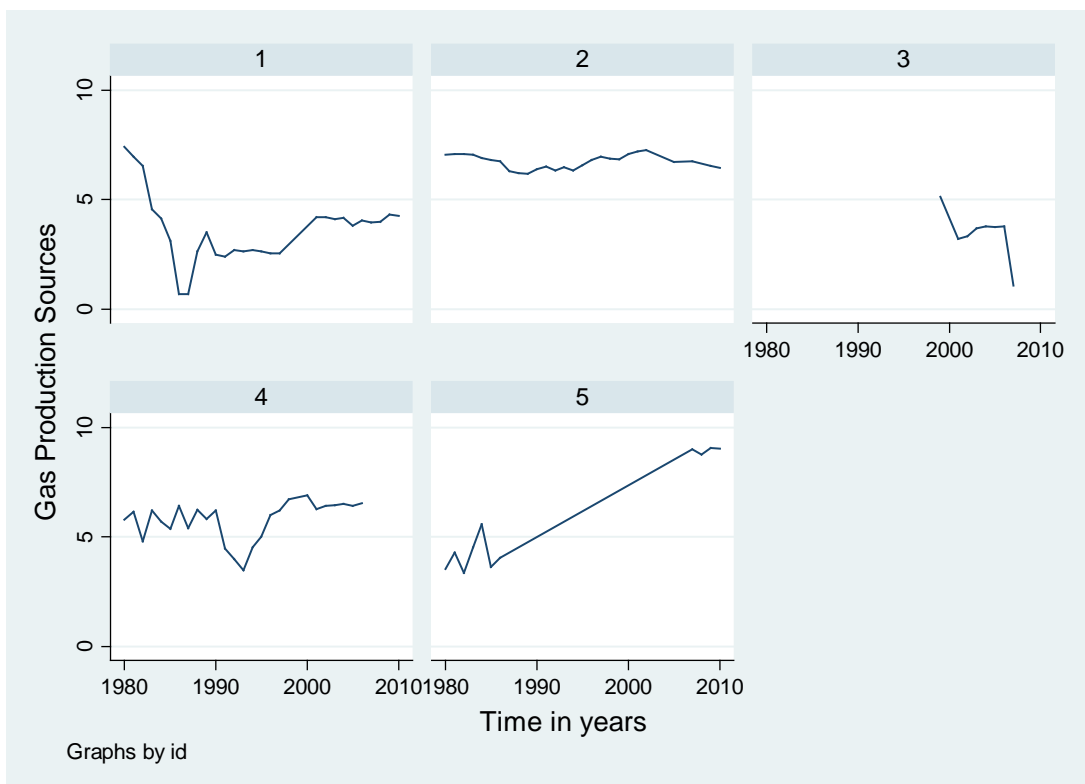

Note: The graphs above show trends for North America, Europe, Africa, Latin America and South East Asia respectively.

Figure 7. Regional gas production.

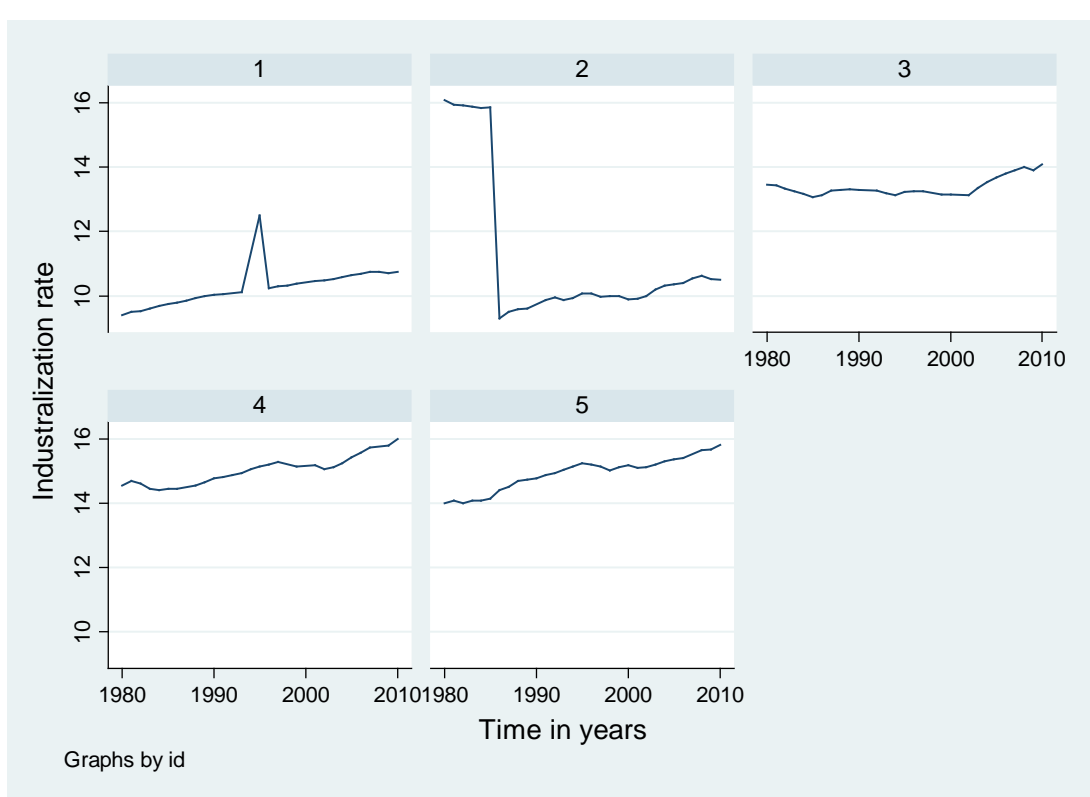

Note: The graphs above show trends for North America, Europe, Africa, Latin America and South East Asia respectively.

Figure 8. Regional industrialization trends.

capital intensive nature of building power plants and accessing resources to power them. This is measured using GDP per capital divided by percentage inflation to deflating for inflation to obtain real wages. Regional specific investment in domestic innovation (Inv. Dom.) was also measured using total investment in research and development in regions in constant US dollars. While regional industrialization rate was regional specific logarithm of GDP in constant USD which will be high for highly industrialized countries. Energy consumption rate (Ene Cons.) was measured using total domestic consumption for countries in regions in Kilowatt hour and finally regional specific energy policy was measured using score values for regional specific participation and implemen- 


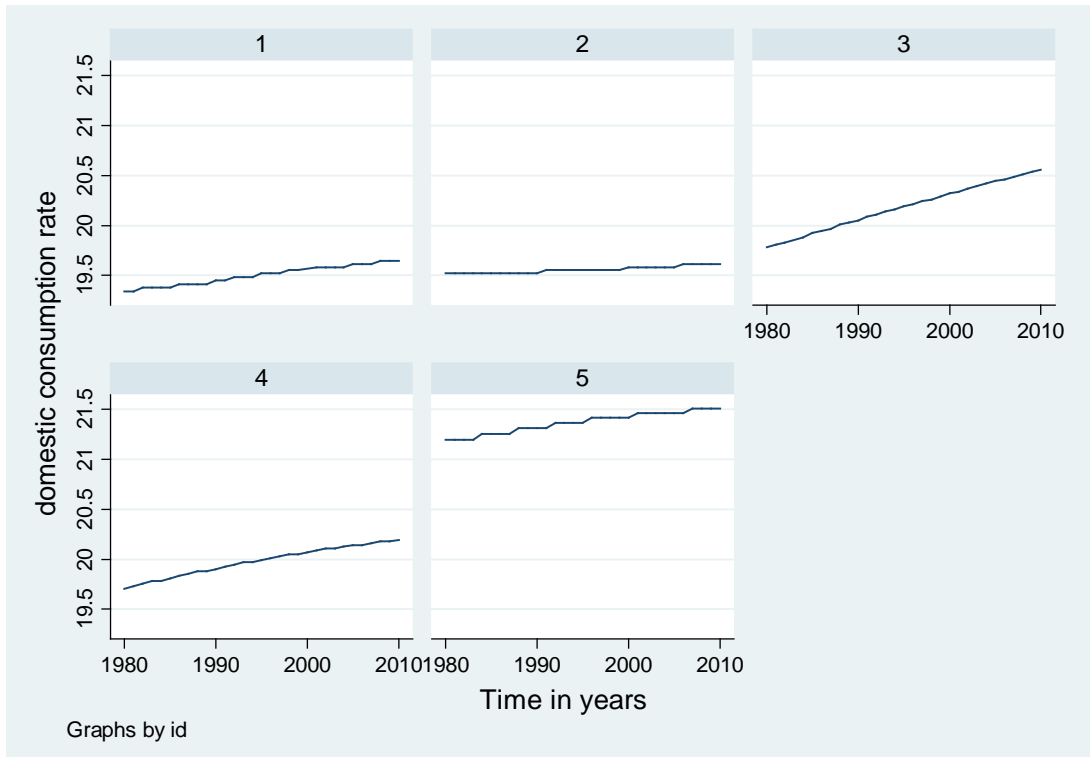

Note: The graphs above show trends for North America, Europe, Africa, Latin America and South East Asia respectively.

Figure 9. Domestic energy consumption across regions.

tation of the Kyoto protocol starting from 1998 when the first inter government panels were set up to 2010 when commitment towards emission reduction and implementation plans were emphasized also using score values of 1 to 3 depending on regional level of implementation and finally using consumption patterns in the pre Kyoto protocol years.

\subsection{Model Specification and Equations}

Energy Diversification will be the number of existing dependable generation sources, while energy policy across regions will be a function of energy diversification and countries across regions signatory and to the Kyoto protocol expressed below as:

$$
\text { Policy = Energy Diversification }+ \text { Kyoto Protocol Signatory }
$$

The reason for this is that policy in countries across regions will be shaped by the need to stem supply interruption through diversifying the generation process as well as reducing greenhouse gases which is one of the aims of the Kyoto accord, which could lead to countries exploring cleaner and possibly cheaper methods of energy generation such as the use of renewable energy sources in the generation process.

Environmental constraints such as the availability of natural resources for the generation process is also taken into consideration, other issues such as size of regions since transmission of energy through long distances is costly due to losses that accompany such circumstances are also a matter of concern and finally regional temperature level are also an issue of concern since temperate regions are likely to need sustained heating supply during cold winter conditions which could be costly and tropical regions are likely to harness cheap solar source if not now but in the future. This allows us to state that environmental constraints to the generation process will be a function of energy resource, regional size and differences in regional temperature levels:

$$
\text { Env. Const. }=\text { Available Energy Resource }+ \text { Regional Size }+ \text { Temperature Levels }
$$

Energy consumption will also be a function of three factors income which will affect how consumers can afford available energy, available supply of energy across regions and aggregate demand across regions which will be a function of population density expressed below as:

$$
\text { Energy Consp. = Income + Energy Supply + Population Density }
$$

Domestic technology will be a function of current technology and investment in technology which will affect technology focus overtime expressed below in Equation (4): 
Domestic Tech $=$ Current Tech + Investment in Technology

Energy generation will be a function of diversification depicted by number of dependable generating sources across regions, environmental constraints, available technology as well as domestic and industrial demands for energy expressed below as:

$$
\text { Energy Generation = Diversification }+ \text { Env. Const. }+ \text { Tech }+ \text { Energy Consp. }
$$

Energy security will be a function of the energy generation process and energy policy across regions which will depict how regions efficiently deploy their resources to provide cheap and sustainable energy across regions:

$$
\text { Energy Security }=(\text { Diversification }+ \text { Env. Const. }+ \text { Tech }+ \text { Energy Consp. }) \text { Policy }
$$

Generation (GEN) and energy security can be written as a function of diversified energy sources across regions expressed as GEN f (SOURCES, DOM. TECH., ENV. CONST. and ENE. CONS.) and ENE SEC f (GEN, POLICY)

Energy security is the regarded as the access to uninterruptible energy supply in regions EU Green Paper 2001, the method of identification is based on the fact that energy security will be a function of diversified generation sources and other factors such as environmental constraints that affect that affect the energy generation and supply process, consumption demands both domestic and industrial, availability of domestic technology since it is easier and cheaper to access technology domestically than oversea, regional specific energy policy which will show how regions are deploying their resources towards achieving cheaper, better, cleaner and more sustainable methods of energy supply and generation and finally access to capital which in this case depicts the cost of acquiring capital across regions.

$$
\begin{gathered}
\text { Growth }_{i t}=A K_{i t}^{\alpha} L_{i t}^{1-\alpha} \\
\text { Growth }_{i t}=A K_{i t}^{\alpha} 1_{i t}^{1-\alpha} \text {. Energy Generation } \\
\text { it }
\end{gathered}
$$

Growth will also be a function of cost of labor, cost of access to capital across regions, the fixed level of technology across regions, energy generation, environmental constraints which often increase the cost of energy generation and supply since it can increase the cost of production particularly for the private sector across regions, and finally domestic and industrial demand for energy across regions since this can affect cost of energy at delivery which can have strong effects on final prices of goods and affect income across regions expressed below as GROWTH $f$ (TECH, CAPITAL, LABOUR and GEN).

The method of estimation used in the study is the seemingly unrelated estimation method, based on the assumption that solving two unrelated equations simultaneously will reduce the bias of the error terms $u_{1 i, t}$ and $u_{2 i, t}$ as shown in the model specification below,

$$
\begin{gathered}
\operatorname{ENSEC}_{i, t}=\alpha_{0}+\alpha_{1} \mathrm{GS}_{i, t}+\alpha_{2} X_{i, t}+u_{1 i, t} \\
\mathrm{GROWTH}_{i, t}=\lambda_{0}+\lambda_{1} \mathrm{LABOUR}_{i, t}+\lambda_{2} \mathrm{CAPITAL}_{i, t}+\lambda_{3} \mathrm{TECH}_{i, t}+\lambda_{4} X_{i, t}+u_{2 i, t}
\end{gathered}
$$

through their interaction in a simultaneous regression model. In this case we study the dynamics between energy supply (energy security) potential threats to such supply such as number of generation sources, environmental factors that affect such supply, availability of technology, consumption rate across regions etc. and also the possible effects of energy generation on economic growth through the investigation of what generation sources were promoting growth across regions using the same set of exogenous variables. The variable year is also included to control for annual differences in energy supply and generation that may affect energy security and growth across regions. We do not believe the model will suffer from mis-specification since it identifies all major factors that affect energy security as well growth across regions.

\subsection{Results}

In this section we present the results for the energy security and growth equations respectively in Table 2 and Table 3 below. Renewable and gas production sources were found to be improving energy security in a significant manner. Investment in domestic technology and energy policy across regions were also found to affect energysecurity in a positive significant manner reducing vulnerability to generation and supply interruption across regions. 
Table 2. Regression showing the potential threats to energy supply.

\begin{tabular}{|c|c|c|c|c|c|}
\hline \multirow{2}{*}{ Variables } & (1) & (2) & (3) & (4) & (5) \\
\hline & Energy Security & Energy Security & Energy Security & Energy Security & Energy Security \\
\hline Cost of Energy & $-1.21^{* * *}(2.45)$ & $-1.33^{* * *}(2.50)$ & $-3.57(2.77)$ & $-1.20^{* * *}(2.39)$ & $-1.18^{* * *}(2.45)$ \\
\hline Energy Consumption & $-2.71^{* * *}(8.10)$ & $-2.13^{* * *}(7.90)$ & $-2.24^{* * *}(6.83)$ & $-2.49^{* * *}(8.42)$ & $-2.78^{* * *}(7.75)$ \\
\hline Dom. Innovation & $0.0002^{* * *}(4.32)$ & $0.0002^{* * *}(4.07)$ & $0.0001^{* * *}(4.20)$ & $0.0003^{* * *}(4.54)$ & $0.0003^{* * *}(4.47)$ \\
\hline Env. Constraint & $-7.93^{* * *}(1.69)$ & $-8.12^{* * *}(1.67)$ & $-4.18^{* *}(1.68)$ & $-8.17^{* * *}(1.72)$ & $-7.48^{* * *}(1.73)$ \\
\hline Indust. Rate & $-8.57^{* * *}(2.52)$ & $-8.03^{* * *}(2.46)$ & $-8.40^{* * *}(2.30)$ & $-1.26^{* * *}(3.91)$ & $-7.53^{* * *}(2.76)$ \\
\hline Energy Policy & $0.93^{* * *}(0.14)$ & $0.92^{* * * *}(0.13)$ & $0.89^{* * *}(0.12)$ & $0.94^{* * * *}(0.16)$ & $0.90^{* * *}(0.13)$ \\
\hline Hydro Production & $4.79(1.06)$ & & & & \\
\hline Coal Production & & 3.11 (1.89) & & & \\
\hline Renewable Prod. & & & $0.01^{* * *}(0.01)$ & & \\
\hline Gas Production & & & & $0.0001^{* *}(4.74)$ & \\
\hline Nuclear Prod. & & & & & $7.65(7.70)$ \\
\hline Year Effect & Yes & Yes & Yes & Yes & Yes \\
\hline Observations & 112 & 113 & 112 & 88 & 113 \\
\hline R-Squared & 0.71 & 0.72 & 0.77 & 0.78 & 0.72 \\
\hline
\end{tabular}

Note: The results presented above show the effect of different energy sources on energy security across regions. Renewable energy has strong effects on energy security and overdependence on gas was found to still be present across regions. Standard errors are in parentheses ${ }^{* * * * *} \mathrm{p}<0.01,{ }^{* * *} \mathrm{p}<0.05$, ${ }^{*} \mathrm{p}<0.1$.

Table 3. Regression showing the impact of various generating sources on growth.

\begin{tabular}{|c|c|c|c|c|c|}
\hline \multirow{2}{*}{ Variables } & (1) & (2) & (3) & (4) & (5) \\
\hline & Log of GDP & Log of GDP & Log of GDP & Log of GDP & Log of GDP \\
\hline Average Wages & $8.00^{* * *}(2.80)$ & $8.13^{* * *}(3.15)$ & $8.32^{* * *}(3.92)$ & $7.72^{* * * *}(2.88)$ & $8.02^{* * * *}(3.04)$ \\
\hline Energy Consumption & $-1.49(9.25)$ & $-5.90(9.93)$ & $5.99(9.64)$ & $-1.34(1.02)$ & $-3.97(9.61)$ \\
\hline Domestic Innovation & $0.0001^{* * *}(4.94)$ & $0.0002^{* * *}(5.11)$ & $0.0002^{* * *}(5.93)$ & $0.0001^{*}(5.48)$ & $0.0003^{* * *}(5.55)$ \\
\hline Env. Constraint & $-0.0002^{* * *}(1.93)$ & $-0.0002^{* * *}(2.10)$ & $-0.0002^{* * *}(2.37)$ & $-0.0002^{* * *}(2.07)$ & $-0.0002^{* * * *}(2.15)$ \\
\hline Indust. Rate & $-1.82^{* * *}(2.88)$ & $-2.33^{* * *}(3.10)$ & $-2.16^{* * *}(3.25)$ & $-2.30^{* * *}(4.72)$ & $-1.67^{* * *}(3.42)$ \\
\hline Energy Policy & $0.77^{* * *}(0.15)$ & $0.78^{* * * *}(0.17)$ & $0.73^{* * * *}(0.17)$ & $0.40^{* *}(0.20)$ & $0.62^{* * *}(0.17)$ \\
\hline Hydro Production & $6.65^{* * *}(1.21)$ & & & & \\
\hline Coal Production & & $-6.78^{* * *}(2.38)$ & & & \\
\hline Renewable Prod. & & & $0.01^{*}(0.001)$ & & \\
\hline Gas Production & & & & $7.65(5.72)$ & \\
\hline Nuclear Prod. & & & & & $0.0003^{* * *}(9.55)$ \\
\hline Year Effect & Yes & Yes & Yes & Yes & Yes \\
\hline Observations & 112 & 113 & 112 & 88 & 113 \\
\hline R-Squared & 0.92 & 0.91 & 0.91 & 0.95 & 0.91 \\
\hline
\end{tabular}

Note: The result above show the effect of generating sources on growth across regions coal production source was having a negative effect on growth. Renewable energy and nuclear production sources promoting growth Standard errors are in parentheses ${ }^{* * *} \mathrm{p}<0.01,{ }^{* * *} \mathrm{p}<0.05,{ }^{*} \mathrm{p}<0.1$. 
Cost of access to energy, energy consumption, environmental constraint and industrialization rate were having a negative significant effect on energy security increasing the risk to generation and supply interruption across regions (see Table 2).

Renewable energy, hydro energy and Nuclear energy sources were found to be promoting economic growth across regions. While industrialization rate have peaked for the developed countries continuous investment in domestic technology and energy policy were found to improve economic growth across regions. Coal production source was having a negative effect, on growth in countries, across regions. Environmental constraint was having a negative effect on economic growth depicting that increased cost of accessing energy resources were still an issue in countries across regions. The variable year was also significant showing that energy generation was having an effect on energy security and growth, the differences in fluctuations in growth and energy security in years were likely not be responsible for changes in energy security.

All the objectives of the study were realized, the question if energy generation was affecting growth across regions was answered although coal production sources were having negative effect on growth, renewable and nuclear source were positively driving growth across regions. Renewable energy sources were found to be most relevant to driving growth across regions, over-dependence on nuclear sources were also having positive implications for growth this will most likely affect developed countries that utilize this source of generation. Finally, some threats were found to negatively affect energy security in general they included the cost of accessing energy, environmental issues associated with the generation process, growing domestic consumption demands and industrial demands for energy.

\section{Discussion and Conclusions}

In this section we discuss the implications of our findings. The world is heading towards another challenging era since global energy demands are on the increase. Threats were found to matter in the energy production and access process. Some threats identified, negatively affect energy security in general including the cost of accessing energy, environmental issues associated with the generation process, growing domestic consumption demands and industrial demands for energy.

It was found that energy generating sources were improving energy security in regions with renewable and gas energy sources that had positive significant effects on mitigating energy generation disruptions across regions. The implication of this finding was that the issue of overdependence on fossil supply sources was probably an issue regions have to take strongly. While gas production were improving, energy security regions were still susceptible to environmental risks such as pollution from green house (gases) and gas supply disruption associated with cost implications and other political factors such as gas channel disputes that could affect gas supply from producing countries to destination countries. Energy generating sources were also found to have implicative consequences for growth across regions with nuclear and renewable energy sources having positive effects on growth. This result was however not same for coal production sources as they were found to have growth reduction effects. This is probably attributable to environmental consequences of using coal leading to reduced use of coal in regional energy generation capabilities in general.

Finally regions were found to depend more and more on renewable energy sources, and this would be particularly true for developed countries and could also have strong implications for developing countries with low income since renewable energy sources are likely to be cheaper and a more reliable means to generate energy with minimal environmental pollution and degrading consequences, in countries across regions. Improving energy security through diversifying generation could also mean improvements in economic growth particularly for the private sector since it could improve private sector-led growth and aid industrialization efforts in countries.

The study supports past findings by [9] who stated that diversification were necessary to improve energy security in general through holding risk-free portfolios to stem risk associated with hikes in fossil prices and the study by [10] who argued that energy policy were important in averting energy crisis since resources for generation were often scarce leading to the competition for the available scarce resources. The findings have strong policy implications for stake holders in the energy industry and for governments, and renewable energy sources are probably a way to go in the future and have far-reaching effects on growth evidence which are evident in their environmental friendliness, sustained use and relative cheapness having obvious implications for developing countries in particular. 


\section{Acknowledgements}

"P. Ojeaga” thanks Bergamo University Italy and Prof. Annalisa Cristini specifically, for funds in obtaining the data, for this work during his Ph.D. research. He also expresses "Thanks" to the Chief Librarian in Watertown MA (Boston) for allowing him to use his favorite corner while collating the data for this study.

\section{References}

[1] International Energy Agency (IEA) (2001) Report 2001.

[2] European Commission (2000) Towards a European Strategy for the Security of Energy Supply. Green Paper, COM769, Brussels.

[3] Cohen, G., Joutz, F. and Loungani, P., (2011) Measuring Energy Security: Trends in the Diversification of Oil and Natural Gas Supplies. IMF Working Paper No. 11/39, Washington, DC.

[4] Bryce, R. (2008) The Dangerous Delusions of “Energy Independence’. Public Affairs, New York.

[5] Le Coq, C. and Paltseva, E. (2008) Common Energy Policy in the EU: The Moral Hazard of the Security of External Supply. SIEPS Report 2008: 1, Stockholm, Sweden

[6] Neumann, A. (2004) Security of Supply in Liberalised European Gas Markets. Diploma Thesis, European University Viadrina, Viadrina.

[7] Neumann, A. (2007) How to Measure Security of Supply? Mimeo, Dresden University of Technology, Dresden.

[8] Annual Energy Outlook (2009) Energy Information Administration Office of Integrated Analysis and Forecasting. U.S. Department of Energy.

[9] Awerbuch, S., Jansen, J.C. and de Vries, H.J. (year) Demonstrating and Building Capacity for Portfolio-Based Energy Planning in Developing Countries. Interim Report Submitted to The Renewable Energy \& Energy Efficiency.

[10] Knox-Hayes, J., Brown, M.A., Sovacool, B.K. and Wang, Y. (2013) Understanding Attitudes toward Energy Security: Results of a Cross-National Survey. Global Environmental Change, 23, 609-622. http://dx.doi.org/10.1016/j.gloenvcha.2013.02.003

[11] Ojeaga, P., Odejimi, D. and Alege, P.O. (2013) Rethinking Regional Energy Policy: Towards Averting AnotherEnergy Crisis. Do Threats Matter in The Supply and Generation Process? Journal of Energy Technologies and Policy, 4, 1-17.

[12] Alexeev, M. and Conrad, R. (2009) The Elusive Curse of Oil. The Review of Economics and Statistics, 91,586-598. http://dx.doi.org/10.1162/rest.91.3.586

[13] Bhattacharyya, S. (2009) Root Causes of African Underdevelopment. Journal of African Economies, 14, 745-780.

[14] Acemoglu, D., Johnson, S. and Robinson, J. (2001) The Colonial Origins of Comparative Development: An Empirical Investigation. American Economic Review, 91, 1369-1401.

[15] Renewable Global Status Report REN21 (2012) Renewable Global Status Report 2006-2012.

[16] Burnside, C. and Dollar, D. (2000) Aid, Policies and Growth. American Economic Review, 90, 847-868. 
Scientific Research Publishing (SCIRP) is one of the largest Open Access journal publishers. It is currently publishing more than 200 open access, online, peer-reviewed journals covering a wide range of academic disciplines. SCIRP serves the worldwide academic communities and contributes to the progress and application of science with its publication.

Other selected journals from SCIRP are listed as below. Submit your manuscript to us via either submit@scirp.org or Online Submission Portal.
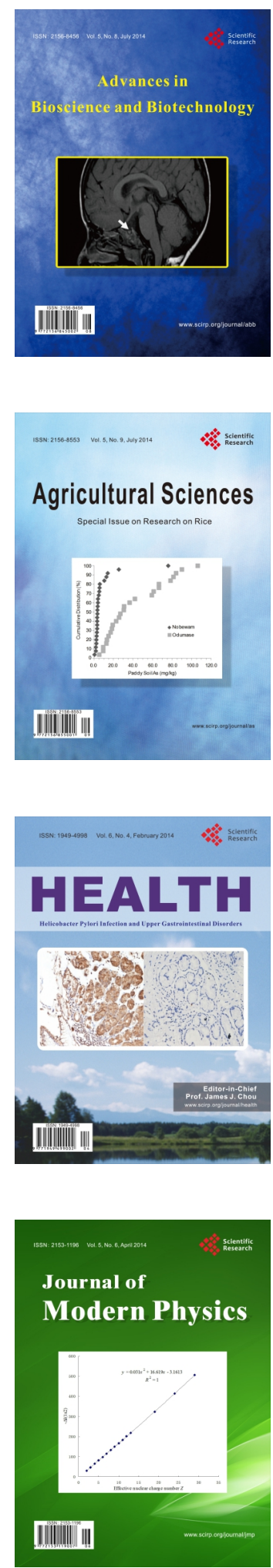
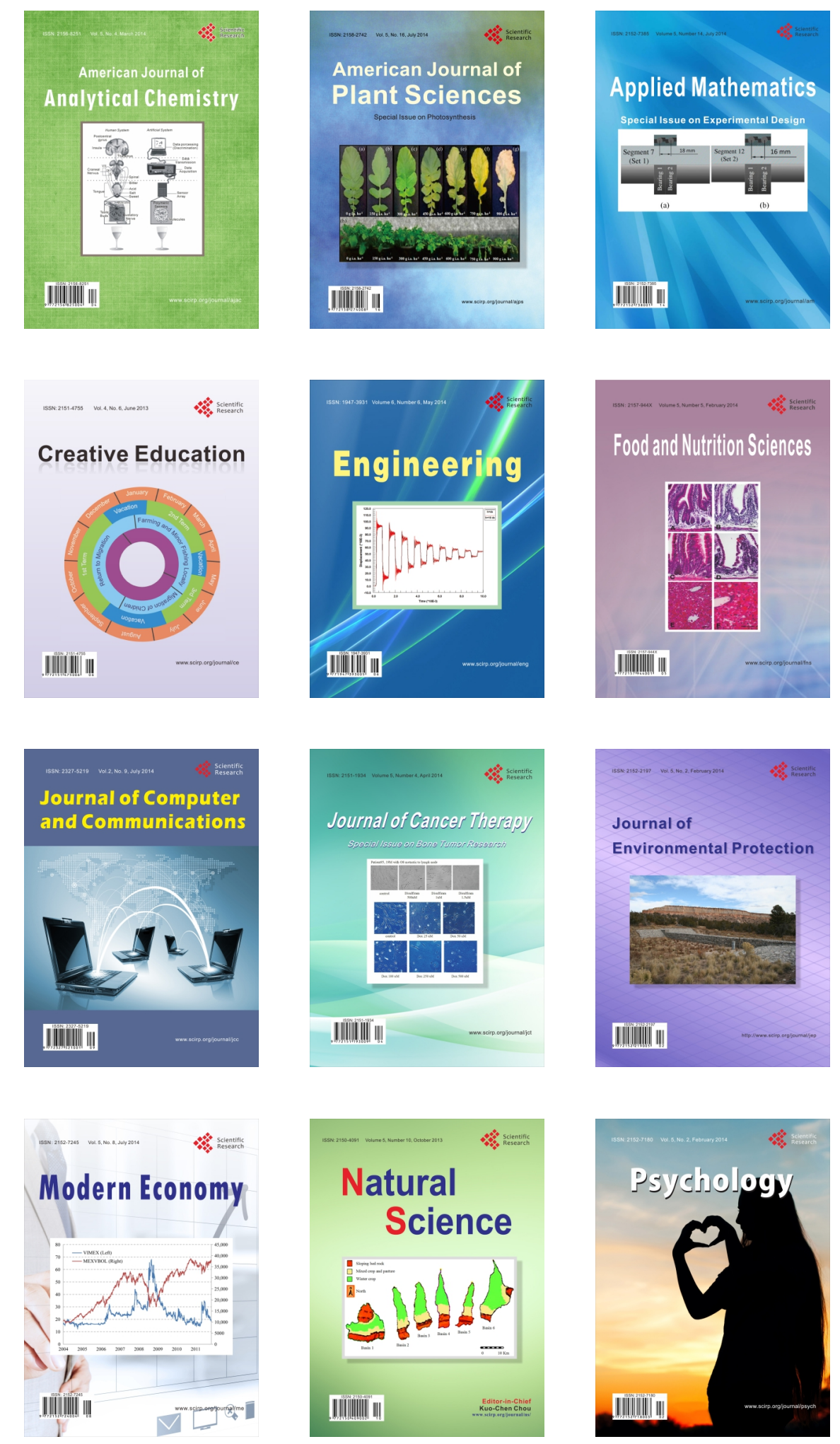